\title{
BMJ Open Effects of beta-blocker therapy on mortality after elective colon cancer surgery: a Swedish nationwide cohort study
}

\author{
Rebecka Ahl, ${ }^{1,2,3}$ Peter Matthiessen, ${ }^{2,4}$ Gabriel Sjölin,, ${ }^{2,4}$ Yang Cao (D) ,2 \\ Göran Wallin, ${ }^{2,4}$ Olle Ljungqvist, ${ }^{2}$ Shahin Mohseni (i) ${ }^{2,4}$
}

To cite: Ahl R, Matthiessen $P$, Sjölin G, et al. Effects of betablocker therapy on mortality after elective colon cancer surgery: a Swedish nationwide cohort study. BMJ Open 2020;10:e036164. doi:10.1136/ bmjopen-2019-036164

- Prepublication history for this paper is available online To view these files, please visit the journal online (http://dx.doi. org/10.1136/bmjopen-2019036164).

Received 03 December 2019 Revised 14 April 2020 Accepted 28 May 2020

Check for updates

C Author(s) (or their employer(s)) 2020. Re-use permitted under CC BY-NC. No commercial re-use. See rights and permissions. Published by BMJ.

${ }^{1}$ Department of Surgery, Karolinska University Hospital, Stockholm, Sweden

${ }^{2}$ School of Health and Medical Sciences, Örebro University,

Örebro, Sweden

${ }^{3}$ Department of Clinical Science, Intervention and Technology, Karolinska Institutet, Stockholm, Sweden

${ }^{4}$ Department of Surgery, Örebro University Hospital, Örebro, Sweden

Correspondence to Dr Shahin Mohseni; mohsenishahin@yahoo.com

\section{ABSTRACT}

Objective Colon cancer surgery remains associated with substantial postoperative morbidity and mortality despite advances in surgical techniques and care. The trauma of surgery triggers adrenergic hyperactivation which drives adverse stress responses. We hypothesised that outcome benefits are gained by reducing the effects of hyperadrenergic activity with beta-blocker therapy in patients undergoing colon cancer surgery. This study aims to test this hypothesis.

Design Retrospective cohort study.

Setting and participants This is a nationwide study which includes all adult patients undergoing elective colon cancer surgery in Sweden over 10 years. Patient data were collected from the Swedish Colorectal Cancer Registry. The national drugs registry was used to obtain information about beta-blocker use. Patients were subdivided into exposed and unexposed groups. The association between beta-blockade, short-term and long-term mortality was evaluated using Poisson regression, Kaplan-Meier curves and Cox regression.

Primary and secondary outcomes Primary outcome of interest was 1-year all-cause mortality. Secondary outcomes included 90-day all-cause and 5-year cancerspecific mortality.

Results The study included 22337 patients of whom $36.1 \%$ were prescribed preoperative beta-blockers. Survival was higher in patients on beta-blockers up to 1 year after surgery despite this group being significantly older and of higher comorbidity. Regression analysis demonstrated significant reductions in 90-day deaths (IRR $0.29,95 \% \mathrm{Cl} 0.24$ to $0.35, \mathrm{p}<0.001$ ) and a $43 \%$ risk reduction in 1-year all-cause mortality (adjusted HR 0.57 , $95 \% \mathrm{Cl} 0.52$ to $0.63, \mathrm{p}<0.001$ ) in beta-blocked patients. In addition, cancer-specific mortality up to 5 years after surgery was reduced in beta-blocked patients (adjusted HR $0.80,95 \% \mathrm{Cl} 0.73$ to $0.88, \mathrm{p}<0.001$ ).

Conclusion Preoperative beta-blockade is associated with significant reductions in postoperative short-term and long-term mortality following elective colon cancer surgery. Its potential prophylactic effect warrants further interventional studies to determine whether beta-blockade can be used as a way of improving outcomes for this patient group.
Strengths and limitations of this study

- This cohort study used a prospectively collected database comprising a $99.5 \%$ national inclusion coverage of all adult patients undergoing elective surgery for colon cancer.

- It is the first beta-blocker study to evaluate a homogeneous surgical patient group with patient selection limited to planned, standardised major abdominal surgery, a diagnosis of colon cancer mainly affecting the elderly and a healthcare system that provides universal care free at the point of use.

- Multivariate regression analysis was carried out to evaluate the association between beta-blocker use and survival following surgery.

- Given the retrospective design, the current study is unable to determine whether the apparent effect of beta-blocker therapy is due to preoperative or postoperative administration or a required combination of the two.

\section{BACKGROUND}

Colon cancer surgery has long been associated with substantial postoperative morbidity and mortality. ${ }^{1-3}$ Figures published by the American College of Surgeons National Surgical Quality Improvement Programme demonstrate that one in four patients suffer complications following colorectal surgery while fatalities run at up to four per cent. Ten per cent of the complications are classified as serious and are of both cardiac and noncardiac nature. ${ }^{4}$ Despite a fall in morbidity, as a result of advancements in perioperative and postoperative colorectal cancer care, the incidence of postoperative deaths has not demonstrated the same change during the past decade. $^{15-7}$

One contributory factor may be the difficulty in controlling postoperative stressrelated events that have been closely linked to the surgery-induced hyperadrenergic state $^{8-10}$ Few effective cardiovascular 
preventative measures are established in non-cardiac surgery and patients with pre-existing coronary artery disease are at particular risk. ${ }^{11-14}$ In addition, the hyperadrenergic state has been linked to insulin resistance, inflammatory responses and immunosuppression leading to an increased risk for postoperative complications and death. ${ }^{15-19}$ Immunosuppression has not only been linked to worsened outcomes in the context of surgery but there is a close relationship between immunosuppression, chronic inflammation and subsequent cancer development. ${ }^{20}$ By reducing adrenergic receptor activation, beta-blockers may decrease physiological stress caused by the insult of major abdominal surgery. Previous studies investigating the relationship between beta-blockade and non-cardiac surgery have tended to lump together several surgical fields. ${ }^{10}$ This methodological approach may affect results and it makes it difficult to draw conclusions about abdominal surgery specifically. Reductions in several severe postoperative complications has been measured in patients on preoperative beta-blockers undergoing surgery for rectal cancer as well as increased survival up to 1 year in the same population. ${ }^{21}$ The authors have previously published results demonstrating a positive effect of preoperative beta-blocker therapy on short-term survival in patients undergoing emergency surgery for colon cancer. ${ }^{22}$ This study investigates whether this effect extends to patients undergoing elective colon cancer resection and whether the effect remains long-term. This may not simply be assumed from previous results since, unlike patients who are forced to undergo emergency intervention, the patient group in this study has already been optimised for surgery. The authors hypothesise that beta-blocker exposure reduces the risk of both shortand long-term postoperative mortality following elective colon cancer surgery.

\section{METHOD}

\section{Study design}

In this retrospective cohort study patients were identified using the Swedish Colorectal Cancer Registry (SCRCR). ${ }^{23}$ The SCRCR is a prospectively collected national quality registry including both surgical and oncological treatments for colorectal cancers. Clinical information, outcomes and demographics are collected from the date of diagnosis and for a period of threeyears. The registry has a $99.5 \%$ nationwide coverage.$^{24}$ In the current study, data for all adults ( $\geq 18$ years) who underwent elective surgery for colon cancer were obtained from the SCRCR. The inclusion period ran from January 2007 to October 2016. Patients who underwent local tumour resection or laparotomy without bowel resection were excluded. Sex, age, body mass index (BMI), American Society of Anesthesiologists (ASA) classification, tumour location, TNM (tumour,node, metastases) classification, surgical approach (open or laparoscopic), hospital length of stay, 90-day and 1-year mortality along with the cause of death were obtained from the registry. The SCRCR does not record comorbidity data. Therefore, comorbidity data was obtained from the National Patient Registry which records diagnoses made both in primary and secondary care. Data on 5-year mortality and cause of death were obtained from the Swedish Causes of Death Registry maintained by the Swedish National Board of Health and Welfare. Death certificates allow for more than one cause of death to be listed with decreasing importance. Colon cancer listed as the first cause of death were classified as cancer-specific deaths.

The study was registered on 7 July 2017 with the Open Database for Research in Sweden. ${ }^{25}$ It received funding from the Örebro University Research Committee (grant number OLL-676701). The principles of the Declaration of Helsinki and the STROBE (Strengthening the Reporting of Observational Studies in Epidemiology) reporting guidelines were adhered to. The authors have no conflicts of interest to disclose. No additional data than that included in this manuscript is available.

\section{Patient and public involvement}

There was no patient or public involvement in this study. Due to time and funding limitations neither patients nor the public were invited to comment on the design or analysis of this research.

\section{Beta-blocker exposure}

Issued beta-blocker prescriptions (ACT codes C07AA, $\mathrm{C} 07 \mathrm{AB}$ and $\mathrm{C} 07 \mathrm{AG}$ ) within a 12 -month preoperative period were obtained from the national drugs registry of the Swedish National Board of Health and Welfare, allowing the subdivision of patients according to betablocker exposure. A 12-month inclusion period was chosen since beta-blockers are rarely discontinued once initiated (most commonly for a cardiovascular indication) and therefore commonly issued on a long-term basis covering up to a 12-month period with a single prescription. The drugs registry is a population-based database containing all prescriptions issued in Sweden. Unique personal identity numbers were used to link electronic prescriptions in the drugs registry to individual patients in the SCRCR. Inclusion criteria for the beta-blocker exposed group was set to patients with collected prescriptions for regular beta-blocker administration that were in active use at the time of surgery. Information regarding dose and generic drug name were also collected. Patients with physician-issued prescriptions that were not collected by the patient were excluded from the beta-blocker exposed group. According to national guidelines set by the Swedish Society of Anesthesiology and Intensive Care, a patient on regular beta-blocker therapy should always receive this on the morning of surgery and if no absolute contraindications exist the medication will be reinstated as soon as possible postoperatively.

\section{Statistical analysis}

Patients' demographic characteristics were presented using descriptive statistical methods and subsequently 
compared between subgroups. Continuous variables were portrayed as means and standard deviations (SD) while categorical and ordinal variables were outlined as counts and percentages or medians and quartiles where suitable. $\chi^{2}$ or Fisher's exact tests were used for comparison between categorical variables and Student's t-test was used for continuous variables with normal distribution. The Mann-Whitney $\mathrm{U}$ test was used for variables with ordinal or asymmetrically distributed continuous data. The primary outcome of interest was 1-year all-cause mortality. Secondary outcomes included 90-day all-cause and 5-year cancer-specific mortality.

The association between beta-blocker use and 90-day all-cause mortality was analysed using Poisson regression with robust standard errors (SE) ${ }^{26}$ Multiple imputation method was used for handling missing values. Potential confounding was adjusted for in the models by including the following covariates: age, sex, ASA classification, cancer stage, Charlson Comorbidity Index, chemotherapy, type of surgical resection and method. Oneyear all-cause and 5-year cancer-specific mortality was illustrated using Kaplan-Meier curves and assessed with Cox proportional hazards regression. The Cox models were adjusted for the same covariates as in the Poisson regression model. In the 1-year all-cause mortality analysis, the event was defined as death of any cause within the specified time and censoring was defined as alive at the end of the specified time period. For 5-year cancerspecific survival analysis, the event was defined as death from colon cancer within five years and the censoring was defined as alive at last follow-up or death from any other cause. Results are reported as incidence rate ratio (IRR) for 90-day mortality and as hazard ratio (HR) for 1-year and 5-year mortality with corresponding $95 \%$ confidence intervals $(\mathrm{CI})$. Tests were considered statistically significant at a two-sided $p$ value of $<0.05$. Analyses were carried out using the SPSS Windows V.25.0 (IBM, Armonk, New York).

\section{RESULTS}

\section{Comparison of group characteristics}

During the 10-year study period 22805 patients underwent elective resection surgery for colon cancer in Sweden. Two per cent $(n=468)$ of patients were excluded due to missing data in several of the collected variables, leaving a total of 22337 patients available for analysis. Out of this cohort, $36.1 \% \quad(n=8072)$ of patients were prescribed regular preoperative beta-blocker therapy. An overwhelming majority of patients $(85 \%)$ were prescribed a beta-1 receptor selective agent, with the most commonly prescribed beta-blocker agent being metoprolol (48.6\%) followed by bisoprolol (19.7\%) and atenolol $(17.0 \%)$. There were statistically significant differences between the groups, with beta-blocker exposed patients demonstrating a higher mean age (75 (SD 9) vs 70 (SD 12) years), a higher mean BMI (26.7 (SD 4.9) vs 25.5 (SD
$4.5))$ and a larger proportion of male patients $(50.0 \%$ vs $47.6 \%$ ) (table 1).

The beta-blocked group was deemed less fit for surgery, as suggested by a larger proportion having an ASA score of $3(44.6 \%$ vs $20.4 \%)$ or $4(4.1 \%$ vs $1.3 \%)$ and more patients with a Charlson Comorbidity Index of 5 and above $(87.3 \%$ vs $66.3 \%)$. Over $70 \%$ of patients in the beta-blocker exposed group had diagnosed cardiovascular disease. The equivalent number in the beta-blocker unexposed group was $27.5 \%$. In both groups, a rightsided hemicolectomy was the most common procedure performed occurring in more than $50 \%$ in each group (table 1). Additionally, patients unexposed to betablocker therapy underwent open surgery to a larger extent $(86.0 \%$ vs $83.8 \%)$ and had a higher incidence of stage IV cancer ( $13.4 \%$ vs $10.1 \%)$ (table 1$)$.

\section{Mortality outcomes}

Seven-hundred and sixteen $(3.21 \%)$ out of the total cohort of 22337 patients died during the 90-day postoperative period. There was a statistically significant difference in mortality rates between the two groups. The beta-blocker unexposed group suffered 316 postoperative deaths $(2.2 \%)$ in the first 30 days compared with the beta-blocker exposed group with only 70 deaths $(0.9 \%)$. This difference remained significant at 90 days $(3.9 \%$ vs $1.9 \%, \mathrm{p}=0.001)$ and at 1 year $(9.6 \%$ vs $8.3 \%, \mathrm{p}=0.001)$ after surgery with numbers needed to treat to benefit of 50 and 77, respectively (table 2). The incidence of cardiac-related deaths was $0.8 \%$ in the total cohort. All causes of death at 90 days, with the exception of cerebrovascular insults, demonstrated lower incidences in the beta-blocker exposed group (table 2).

Patients exposed to beta-blockers had a 90-day mortality risk less than one-third of those who were unexposed (adjusted IRR 0.29, 95\% CI: 0.24 to $0.35, \mathrm{p}<0.001$ ). Both ASA class 3 and 4 as well as cancer stage IV demonstrated major increases in the risk of death within the immediate postoperative period (table 3 ).

The protective effect of beta-blockade appeared to remain at one year after surgery with a risk reduction of $43 \%$ (adjusted HR $0.57,95 \%$ CI 0.52 to $0.63, \mathrm{p}<0.001$ ) (table 4, figure 1). Adjuvant chemotherapy and a laparoscopically carried out procedure were also linked to increased chance of survival at oneyear after elective cancer resection surgery. Following a Cox regression analysis, beta-blocked patients also showed reduced cancerspecific mortality up to five years after surgery with a $20 \%$ risk reduction (adjusted HR 0.80, 95\% CI 0.73 to 0.88 , $\mathrm{p}<0.001$ ) (figure 2).

\section{DISCUSSION}

The results of this large, nationwide cohort study demonstrate that beta-blocker therapy in elective surgery for colon cancer is strongly associated with reduced incidences of death not only in the immediate postoperative period but also long-term. Ninety-day all-cause mortality in 


\begin{tabular}{|c|c|c|c|}
\hline & $\begin{array}{l}\mathrm{BB}^{-} \\
n=14265\end{array}$ & $\begin{array}{l}\mathrm{BB}^{+} \\
\mathrm{n}=8072\end{array}$ & $P$ value \\
\hline Male sex, $n(\%)$ & 6794 (47.6) & $4039(50.0)$ & 0.001 \\
\hline $\begin{array}{l}\text { Age in years, } \\
\text { mean (SD) }\end{array}$ & $70(12)$ & $75(9)$ & $<0.001$ \\
\hline $\begin{array}{l}\text { Age in years, } \\
\text { median (Q1, Q3) }\end{array}$ & $72(63,79)$ & $76(70,82)$ & \\
\hline BMI, mean (SD) & $25.5(4.5)$ & $26.7(4.9)$ & $<0.001$ \\
\hline $\begin{array}{l}\text { BMI, median (Q1, } \\
\text { Q3) }\end{array}$ & $\begin{array}{l}24.9 \\
(22.6,27.8)\end{array}$ & $\begin{array}{l}26.1 \\
(23.5,29.4)\end{array}$ & \\
\hline
\end{tabular}

ASA classification, $\mathrm{n}(\%)$

$\begin{array}{lcc}1 & 2932(20.6) & 162(2.0) \\ 2 & 7962(55.8) & 3851(47.7) \\ 3 & 2913(20.4) & 3597(44.6) \\ 4 & 182(1.3) & 333(4.1) \\ \text { Missing } & 276(1.9) & 127(1.6)\end{array}$

Type of beta-

blocker, n (\%)

$\begin{array}{lll}\text { Atenolol } & - & 1370(17.0) \\ \text { Bisoprolol } & - & 1591(19.7) \\ \text { Metoprolol } & - & 3926(48.6) \\ \text { Other } & - & 1185(14.7)\end{array}$

Surgical resection $\mathrm{n}(\%)$

$<0.001$

\begin{tabular}{|c|c|c|c|}
\hline $\begin{array}{l}\text { lleocecal } \\
\text { resection }\end{array}$ & $139(1.0)$ & $77(1.0)$ & \\
\hline $\begin{array}{l}\text { Right } \\
\text { hemicolectomy }\end{array}$ & $7733(54.2)$ & $4672(57.9)$ & \\
\hline $\begin{array}{l}\text { Resection of } \\
\text { transverse colon }\end{array}$ & $265(1.9)$ & $182(2.3)$ & \\
\hline $\begin{array}{l}\text { Left } \\
\text { hemicolectomy }\end{array}$ & $1695(11.9)$ & $843(10.4)$ & \\
\hline $\begin{array}{l}\text { Resection of } \\
\text { sigmoid colon }\end{array}$ & $3612(25.3)$ & 1847 (22.9) & \\
\hline Total colectomy & $569(4.0)$ & $239(3.0)$ & \\
\hline Hartmann's & $252(1.8)$ & $212(2.6)$ & \\
\hline \multicolumn{2}{|c|}{ Surgical approach, n (\%) } & & $<0.001$ \\
\hline Open & $12271(86.0)$ & 6764 (83.8) & \\
\hline Laparoscopic & $1994(14.0)$ & 1308 (16.2) & \\
\hline $\begin{array}{l}\text { Adjuvant } \\
\text { chemotherapy, } \\
\text { n (\%) }\end{array}$ & $3517(24.6)$ & $1155(14.3)$ & $<0.001$ \\
\hline Cancer stage n (\%) & & & $<0.001$ \\
\hline I & $2191(15.4)$ & 1493 (18.5) & \\
\hline II & $5475(38.4)$ & 3195 (39.6) & \\
\hline III & 4691 (32.9) & $2571(31.9)$ & \\
\hline IV & $1908(13.4)$ & $813(10.1)$ & \\
\hline
\end{tabular}

$\mathrm{T}, \mathrm{N}$ and $\mathrm{M}$ classification, $\mathrm{n}(\%) \quad<0.001$

Continued

\begin{tabular}{|c|c|c|c|}
\hline & $\begin{array}{l}B^{-} \\
n=14265\end{array}$ & $\begin{array}{l}\mathrm{BB}^{+} \\
\mathrm{n}=8072\end{array}$ & $P$ value \\
\hline $\mathrm{T} 1-2$ & 2700 (18.9) & $1796(22.2)$ & \\
\hline T3 & $8664(60.7)$ & $4815(59.7)$ & \\
\hline $\mathrm{T} 4$ & $2869(20.1)$ & $1457(18.1)$ & \\
\hline N1-2 & $6117(42.9)$ & $3166(39.2)$ & \\
\hline M1 & $1907(13.4)$ & $813(10.1)$ & \\
\hline \multicolumn{2}{|c|}{ Charlson Comorbidity Index } & & $<0.001$ \\
\hline$\leq 2$ & $701(4.9)$ & $33(0.4)$ & \\
\hline $3-4$ & $4111(28.8)$ & $996(12.3)$ & \\
\hline$\geq 5$ & $9453(66.3)$ & $7043(87.3)$ & \\
\hline $\begin{array}{l}\text { Cardiovascular } \\
\text { disease, } \mathrm{n}(\%)^{*}\end{array}$ & 3926 (27.5) & $5880(72.8)$ & $<0.001$ \\
\hline $\mathrm{CHF}$ & $342(2.4)$ & $1226(15.2)$ & \\
\hline Arrhythmia & $862(6.0)$ & $2400(29.7)$ & \\
\hline Ml & $313(2.2)$ & $1349(16.7)$ & \\
\hline Hypertension & $2878(20.2)$ & $4411(54.6)$ & \\
\hline Other & $425(3.0)$ & $251(3.1)$ & \\
\hline $\begin{array}{l}\text { Coagulopathic } \\
\text { disease, n (\%) }\end{array}$ & $103(0.7)$ & $162(2.0)$ & $<0.001$ \\
\hline $\begin{array}{l}\text { Respiratory } \\
\text { disease, n (\%) }\end{array}$ & $1120(7.9)$ & $847(10.5)$ & $<0.001$ \\
\hline $\begin{array}{l}\text { Cerebrovascular } \\
\text { disease, } \mathrm{n}(\%)\end{array}$ & $616(4.3)$ & $723(9.0)$ & $<0.001$ \\
\hline $\begin{array}{l}\text { Renal failure, } n \\
(\%)\end{array}$ & $1677(11.8)$ & $1502(18.6)$ & $<0.001$ \\
\hline $\begin{array}{l}\text { Diabetes mellitus, } \\
\mathrm{n}(\%)\end{array}$ & $1327(9.3)$ & $1659(20.6)$ & $<0.001$ \\
\hline
\end{tabular}

* Represents the total number of patients with cardiovascular disease. The total is lower than the listed cardiovascular conditions combined due to some patients having more than one cardiovascular condition.

ASA, American Society of Anesthesiologists; $\mathrm{BB}^{+}$, beta-blocker positive; $\mathrm{BB}^{-}$, beta-blocker negative; $\mathrm{BMI}$, body mass index; $\mathrm{CHF}$, congestive heart failure; MI, myocardial infarction; n/a, not applicable; Q1, first quartile; $\mathrm{Q} 3$, third quartile; T, N and $\mathrm{M}$, tumour, node and metastases.

beta-blocker unexposed patients was $3.9 \%$ and the equivalent figure in beta-blocker exposed patients was $1.9 \%$ $(\mathrm{p}=0.001)$. After adjustment for confounding factors, patients on preoperative beta-blocker therapy showed a $70 \%$ relative risk reduction in 90-day mortality compared with patients who did not receive beta-blockers. In the context of long-term survival, beta-blocker use was associated with a $43 \%$ risk reduction in 1-year overall mortality (HR $0.57,95 \%$ CI 0.52 to $0.63, \mathrm{p}<0.001$ ). The protective effect of beta-blockade on mortality was also seen for 5 -year cancer-specific mortality (HR $0.80,95 \%$ CI 0.73 to $0.88, \mathrm{p}<0.001)$.

The physical trauma of surgery triggers hypothalamic activation of the sympathetic autonomic nervous system with subsequent surges in catecholamine secretion, leading to stress responses causing activation of multiple 
Table 2 Clinical outcomes

\begin{tabular}{|c|c|c|c|}
\hline & $\begin{array}{l}B^{-} \\
n=14265\end{array}$ & $\begin{array}{l}\mathrm{BB}^{+} \\
\mathrm{n}=8072\end{array}$ & $P$ value \\
\hline \multicolumn{4}{|l|}{ Hospital length of stay } \\
\hline Days, mean (SD) & $9(10)$ & $10(10)$ & $<0.001$ \\
\hline $\begin{array}{l}\text { Days, median (Q1, } \\
\text { Q3) }\end{array}$ & $6(5,10)$ & $7(5,11)$ & \\
\hline
\end{tabular}

\begin{tabular}{|c|c|c|c|}
\hline \multicolumn{4}{|c|}{ All-cause mortality, $\mathrm{n}(\%)$} \\
\hline 30 days & $316(2.2)$ & $70(0.9)$ & $<0.001$ \\
\hline 90 days & 559 (3.9) & $157(1.9)$ & 0.001 \\
\hline 1 year & $1375(9.6)$ & $674(8.3)$ & 0.001 \\
\hline \multicolumn{4}{|c|}{ Cause-specific mortality at 30 days, $n(\%)$} \\
\hline Cardiovascular & $92(0.6)$ & $20(0.2)$ & $<0.001$ \\
\hline Respiratory & $45(0.3)$ & $11(0.1)$ & 0.01 \\
\hline Sepsis & $37(0.3)$ & $7(0.1)$ & 0.005 \\
\hline Cerebrovascular & $3(0.0)$ & $4(0.0)$ & 0.247 \\
\hline Multiorgan failure & $118(0.8)$ & $26(0.3)$ & $<0.001$ \\
\hline Unknown & $21(0.1)$ & $2(0.0)$ & 0.006 \\
\hline
\end{tabular}

Cause-specific mortality at 90 days, $n(\%)$

\begin{tabular}{|c|c|c|c|}
\hline Cardiovascular & $133(0.9)$ & $46(0.6)$ & 0.004 \\
\hline Respiratory & $66(0.5)$ & $18(0.2)$ & 0.005 \\
\hline Sepsis & $41(0.3)$ & $7(0.1)$ & 0.002 \\
\hline Cerebrovascular & $4(0.0)$ & $4(0.0)$ & 0.414 \\
\hline Multiorgan failure & $291(2.0)$ & $80(1.0)$ & $<0.001$ \\
\hline Unknown & $22(0.2)$ & $2(0.0)$ & 0.005 \\
\hline \multicolumn{4}{|c|}{ Colon cancer-specific mortality, $\mathrm{n}(\%)$} \\
\hline Up to 5 years & 1586 (11.1) & 776 (9.6) & $<0.001$ \\
\hline
\end{tabular}

$\mathrm{BB}^{+}$, beta-blocker positive; $\mathrm{BB}^{-}$, beta-blocker negative; $\mathrm{Q} 1$, first quartile; Q3, third quartile.

organ systems. Adrenoceptors serve a regulating cardiovascular purpose but also serve other organ systems and metabolic and inflammatory networks. ${ }^{8}$ Although a natural response to injury, the activation of adrenoceptors has been linked to an increased risk of death and there is a close relationship between patient epinephrine levels at hospital admission and mortality risk following traumatic injury. ${ }^{1527}$ The complex role of catecholamines contributes to the understanding of the association between physiological trauma and adverse effects such as cardiovascular overload, insulin resistance and increased inflammatory activation and hypercoagulability. ${ }^{13}$ A plausible explanation to increased mortality in the drug-naïve patients could lie in the risk of such adverse events. In elective surgery, blocking of epinephrine release by thoracic epidural has shown to reduce insulin resistance by almost half. ${ }^{18}$ Insulin resistance and hyperglycaemia in surgery has demonstrated a close relationship to the development of complications especially infections and sepsis. ${ }^{19}$ Controlling insulin resistance has been brought forward as a key mechanism behind the success of the Enhanced Recovery After Surgery protocols. ${ }^{28}$ In vivo, the rise in
Table 3 Incidence rate ratio (IRR) for 90-day mortality

\begin{tabular}{|lcc|}
\hline & IRR $(\mathbf{9 5 \%} \mathbf{C l})$ & P value \\
\hline Preoperative BB & $0.29(0.24$ to 0.35$)$ & $<0.001$ \\
Age & $1.03(1.02$ to 1.04$)$ & $<0.001$ \\
Female sex & $0.73(0.63$ to 0.84$)$ & $<0.001$
\end{tabular}

ASA classification

\begin{tabular}{|c|c|c|}
\hline 1 & Ref & - \\
\hline 2 & 1.99 (1.31 to 3.02$)$ & 0.001 \\
\hline 3 & 6.11 (4.04 to 9.23$)$ & $<0.001$ \\
\hline 4 & 14.36 (9.14 to 22.55$)$ & $<0.001$ \\
\hline \multicolumn{3}{|c|}{ Charlson Comorbidity Index } \\
\hline$\leq 2$ & Ref & - \\
\hline $3-4$ & 1.00 (0.35 to 2.84$)$ & 0.996 \\
\hline$\geq 5$ & 1.25 (0.44 to 3.57$)$ & 0.682 \\
\hline \multicolumn{3}{|l|}{ Cancer stage } \\
\hline I & Ref & - \\
\hline II & 1.31 (1.00 to 1.72$)$ & 0.054 \\
\hline III & 2.30 (1.74 to 3.03$)$ & $<0.001$ \\
\hline IV & 4.68 (3.56 to 6.15$)$ & $<0.001$ \\
\hline \multicolumn{3}{|l|}{ Surgical approach } \\
\hline Open & Ref & - \\
\hline Laparoscopic & 0.65 (0.49 to 0.86$)$ & 0.002 \\
\hline \multicolumn{3}{|l|}{ Surgical resection } \\
\hline lleocecal resection & Ref & - \\
\hline Right hemicolectomy & 0.75 (0.48 to 1.18$)$ & 0.217 \\
\hline $\begin{array}{l}\text { Resection of } \\
\text { transverse colon }\end{array}$ & 0.66 (0.35 to 1.22$)$ & 0.184 \\
\hline Left hemicolectomy & 0.76 (0.46 to 1.23$)$ & 0.262 \\
\hline $\begin{array}{l}\text { Resection of sigmoid } \\
\text { colon }\end{array}$ & 0.55 (0.35 to 0.89$)$ & 0.014 \\
\hline Total colectomy & 0.93 (0.53 to 1.62$)$ & 0.784 \\
\hline Hartmann's & 0.71 (0.40 to 1.26$)$ & 0.241 \\
\hline Adjuvant chemotherapy & 0.10 (0.06 to 0.17$)$ & $<0.001$ \\
\hline
\end{tabular}

Poisson regression model with robust SEs. Multiple imputation method was used for missing values. All results adjusted for all variables in the table.

ASA, American Society of Anesthesiologists; BB, beta-blocker.

plasma catecholamines during surgery can be linked to surgery-related stress responses and adrenergic activation is maintained beyond the end of the procedure. ${ }^{29}$ Such observations lead to the hypothesis that maintained administration of preoperatively prescribed beta-blockers could serve a prophylactic role and improve clinical outcomes for patients undergoing complex operations such as colon cancer surgery. The proposed mechanism of action is blockage and attenuation of catecholaminemediated stress responses initiated by major surgery.

The benefits of beta-blockers have been demonstrated in multiple trials in the context of cardiac surgery. ${ }^{30}$ In elective cardiothoracic surgery, the use of perioperative 
Table 4 HR for 1-year mortality

\begin{tabular}{lcc}
\hline & Adjusted HR (95\% Cl) & P value \\
\hline Preoperative BB & $0.57(0.52$ to 0.63$)$ & $<0.001$ \\
\hline Age & $1.03(1.02$ to 1.04$)$ & $<0.001$ \\
\hline Female sex & $0.91(0.83$ to 1.00$)$ & 0.038 \\
\hline ASA Classification & & \\
\hline
\end{tabular}

\begin{tabular}{|c|c|c|}
\hline 1 & Ref & - \\
\hline 2 & 1.63 (1.33 to 2.01$)$ & $<0.001$ \\
\hline 3 & 3.05 (2.47 to 3.76$)$ & $<0.001$ \\
\hline 4 & 6.85 (5.27 to 8.90$)$ & $<0.001$ \\
\hline \multicolumn{3}{|c|}{ Charlson Comorbidity Index } \\
\hline$\leq 2$ & Ref & - \\
\hline $3-4$ & $0.52(0.34$ to 0.79$)$ & 0.002 \\
\hline$\geq 5$ & 0.67 (0.43 to 1.04$)$ & 0.073 \\
\hline \multicolumn{3}{|l|}{ Cancer stage } \\
\hline I & Ref & - \\
\hline II & 1.40 (1.16 to 1.70$)$ & 0.001 \\
\hline III & 3.17 (2.63 to 3.83 ) & $<0.001$ \\
\hline IV & 9.43 (7.83 to 11.35$)$ & $<0.001$ \\
\hline \multicolumn{3}{|l|}{ Surgical approach } \\
\hline Open & Ref & - \\
\hline Laparoscopic & 0.61 (0.51 to 0.72$)$ & $<0.001$ \\
\hline \multicolumn{3}{|l|}{ Surgical resection } \\
\hline Ileocecal resection & Ref & - \\
\hline Right hemicolectomy & 0.63 (0.47 to 0.86$)$ & 0.003 \\
\hline $\begin{array}{l}\text { Resection of } \\
\text { transverse colon }\end{array}$ & 0.65 (0.44 to 0.97$)$ & 0.033 \\
\hline Left hemicolectomy & 0.48 (0.34 to 0.67$)$ & $<0.001$ \\
\hline $\begin{array}{l}\text { Resection of sigmoid } \\
\text { colon }\end{array}$ & 0.38 (0.28 to 0.53$)$ & $<0.001$ \\
\hline Total colectomy & 0.74 (0.52 to 1.07$)$ & 0.110 \\
\hline Hartmann's & 0.69 (0.48 to 1.00$)$ & 0.047 \\
\hline Adjuvant chemotherapy & $0.37(0.31$ to 0.44$)$ & $<0.001$ \\
\hline
\end{tabular}

All results adjusted for all variables in the table.

ASA, American Society of Anesthesiologists; BB, beta-blocker.

or early postoperative beta-blockade is accepted as part of standardised care with level B evidence supporting reduced negative cardiac events. Such measures are endorsed by the American College of Cardiology and American Heart Association (ACC/AHA) guidelines. ${ }^{31}$ Whether this effect is sustained in non-cardiac surgery is under evaluation. However, the Agency for Healthcare Research and Quality's evidence report summarises the use of perioperative beta-blockers as the second-highestrated safety practice protecting against surgical morbidity and mortality. ${ }^{32}$

Favourable effects of beta-blockade on postoperative deaths in patients undergoing non-cardiac surgery have been demonstrated. In the randomised, double-blinded, placebo-controlled trial by Mangano et al patients treated with perioperative and postoperative atenolol demonstrated significant reductions in overall mortality up to two years following hospital discharge. This study included patients undergoing elective neurosurgical, orthopaedic, major vascular and abdominal surgical procedures. ${ }^{33}$ Furthermore, Lindenauer $e t$ al published their retrospective study with results based on a cohort of over 700000 patients undergoing non-cardiac surgery. Their study demonstrated a significant reduction in hospital deaths of between $29 \%$ to $42 \%$ in patients with a raised Revised Cardiac Risk Index (RCRI) and on beta-blockade. The beneficial effect was limited to patients with a RCRI of at least two. ${ }^{9}$ Similarly, Kwon and colleagues showed, in a cohort of over 8000 patients undergoing elective abdominal surgery, that failure to continue regular preoperative beta-blocker therapy during and following surgery led to increased adverse events. In patients with an increased cardiac risk (RCRI >2) the rate of adverse events was increased sixfold, compared with the observed twofold increase for patients with a RCRI $\leq 2 .{ }^{10}$

In the current study, there were significantly fewer cardiovascular-related deaths in those exposed to preoperative beta-blocker therapy $(0.6 \%$ vs $0.9 \%, \mathrm{p}=0.004)$ despite a higher prevalence in cardiovascular disease in this group. The current findings do, however, contrast the randomised controlled Perioperative Ischemic Evaluation (POISE) trial by Devereaux, where no effect on mortality could be detected despite a reduction in cardiovascular adverse events in their beta-blocked cohort. ${ }^{34}$ Similar non-significant results in mortality to that of the POISE trial have been reproduced by others. ${ }^{16} 3536$ One possible explanation for previous studies demonstrating both significant and non-significant results with regards to mortality could be due to the lack of discrimination between different surgical indications and procedures. For example, the POISE trial included three major surgical fields (orthopaedic, abdominal and vascular procedures) under the umbrella term of 'non-cardiac' surgery. This heterogeneity of different surgical patient populations, diseases within each of these surgical fields and the procedures performed is an important limitation and makes it difficult to draw conclusions about any specific surgical subgroup. For this reason, the current study opted to focus specifically on patients subjected to elective abdominal surgery for colon cancer thus yielding a more homogeneous surgical study population.

In addition to their protective role in cardiovascular deaths, beta-blocker use was also associated with a reduced incidence in early deaths caused by respiratory complications, sepsis and multiorgan failure. In line with this is previous evidence demonstrating an association between changes in immune response and physiological stress. In animal models, beta-receptor activation has demonstrated an important immunomodulating role in the context of physiological stress. ${ }^{37}$ Beta-blocker administration has shown a down-regulation of proinflammatory factors such as interleukin- 6 and tumour necrosis 


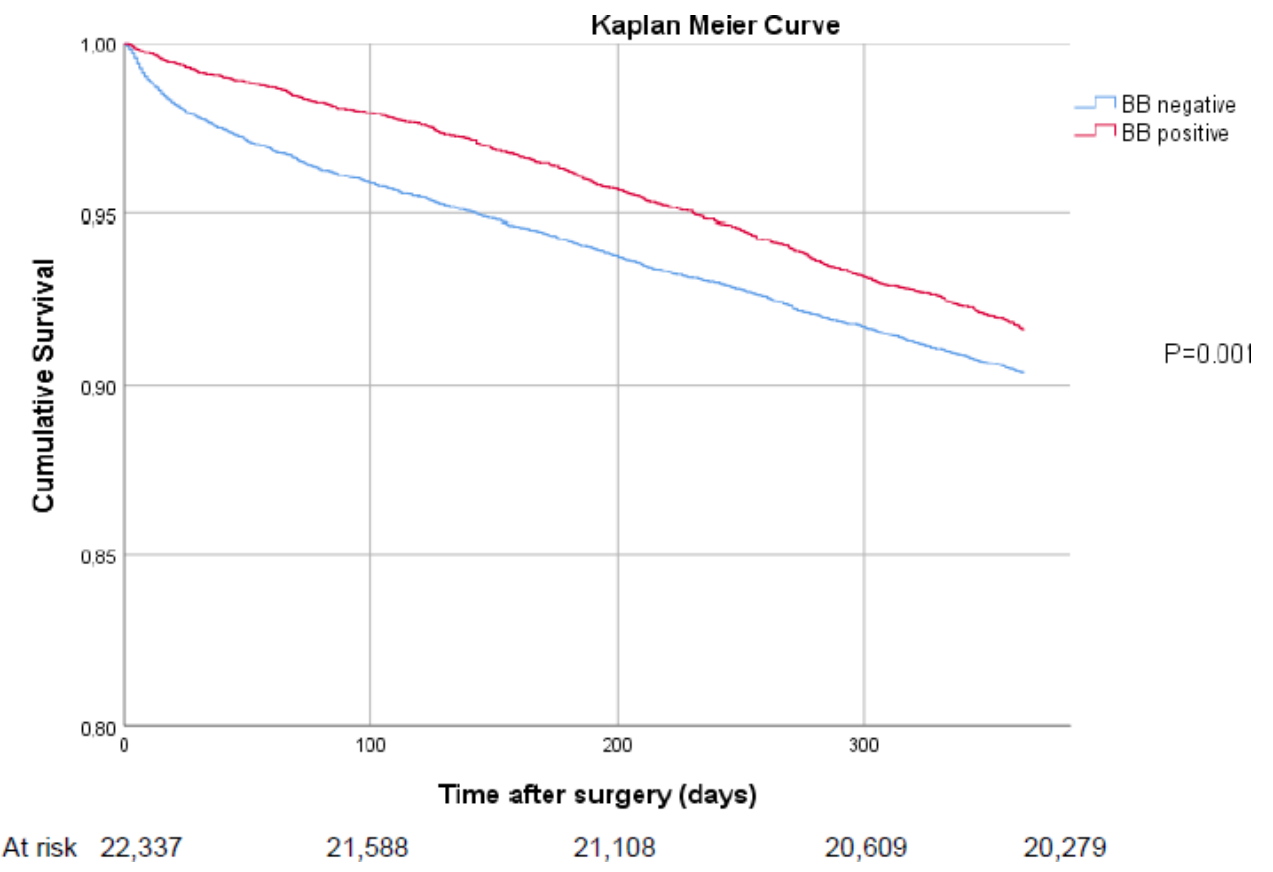

Figure 1 Kaplan-Meier graph of 1-year all-cause mortality.

factor- $\alpha{ }^{1516}$ The current study provides further support for a possible anti-inflammatory effect of beta-blockade.

Despite the observed difference in cardiovascular events, there was no observed difference in cerebrovascular deaths $(\mathrm{p}=0.414)$. The association between betablockade and an increased risk of stroke was raised in 2008 in the POISE trial. ${ }^{34}$ The lack of such results in the current study is, however, in line with more recent findings. Obeid and colleagues found no link between beta-blocker therapy and stroke risk in patients preprocedurally treated with beta-blockers for more than
30 days. ${ }^{38}$ This might be explained by the beta-blocker dose administered: in the POISE study patients received $200 \mathrm{mg}$ extended-release metoprolol daily, ${ }^{34}$ whereas the highest daily dose prescribed for patients in the current study was $125 \mathrm{mg}$ metoprolol with the majority receiving a dose of $50 \mathrm{mg}$. Additionally, an overwhelming majority of beta-blocker exposed patients in the current study had received the drug for at least 12 months prior to surgery. This contrasts with the POISE trial where beta-blocker treated patients were drug-naïve up until drug-initiation immediately before surgery, suggesting that a period of

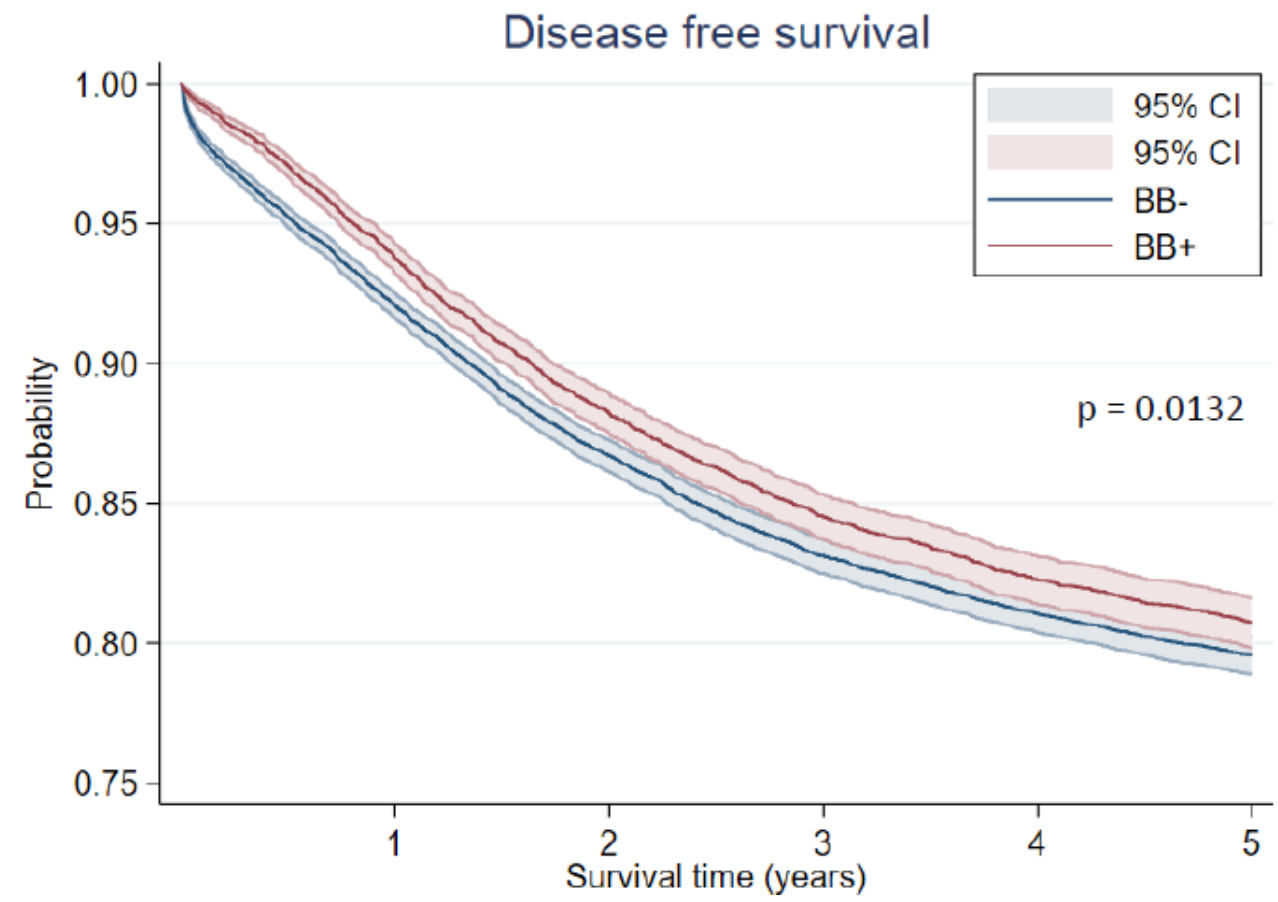

Figure 2 Kaplan-Meier graph of 5-year cancer-specific mortality. BB-, beta-blocker negative; BB+, beta-blocker positive. 
adjustment to the drug may be beneficial prior to the patient undergoing surgery.

The protective association of preoperative beta-blocker therapy and mortality remained beyond the immediate postoperative period and a significant association could be observed at oneyear after surgery still. In addition, patients on beta-blockers also showed an $20 \%$ reduced risk of colon cancer-specific mortality up to five years following surgery. The link between beta-blockade and cancer has previously been under discussion. In 2015, Childers et al published a meta-analysis suggesting that the risk of breast cancer-related deaths could be reduced with the use of beta-blockers. ${ }^{39}$ Such results have been further supported by animal models implicating beta-adrenoceptors in the modulation of breast cancer metastasis. ${ }^{40}$ The association has been extended from breast cancer to other cancer types including colon cancer where beta-blocker therapy has been associated with longer survival for patients with stage 4 disease. ${ }^{41}$ Previous data suggest that stress-related simulation through beta-adrenergic activation might contribute towards cancer growth progression which provides a possible underlying mechanism of action. ${ }^{42}$ In addition, there is evidence suggesting that events, such as anti-inflammatory and anti-adrenergic drug administration, occurring during the perioperative period may affect the risk of cancer progression following surgery. ${ }^{43}$ For example, the preoperative administration of propranolol has shown to attenuate biomarkers of breast cancer metastasis in a blinded randomised trial. ${ }^{44}$ Results have, however, not been unanimous and immortal time bias has been suggested to underlie previously demonstrated beneficial effects of beta-blockade. ${ }^{45-47}$ In addition to the risk of immortal time bias, retrospective studies including the current study risk suffering systematic errors from the chosen definition of cancer-specific mortality and survival. The chosen definition of cancer-specific death for the current study was that of a registered death with colon cancer listed as the primary cause of death. This method relies on the accuracy of death certificates which has been shown to vary. Therefore, the outlined results regarding cancer-specific mortality in the current study have to be interpreted with caution. The results of the current study, together with previous results, do however support the need for a prospective interventional design.

The study presented possesses several strengths including the use of information from a prospectively collected database comprising a $99.5 \%$ national inclusion coverage of all colon cancer patients from a health system that provides universal care; and the focus on standardised, major abdominal surgery for a single type of cancer mainly affecting the elderly population. The results can, however, only be used to draw conclusions about an associative relationship. An interventional design is required to be able to suggest causality and is strongly encouraged by the authors. There are limitations to this study that require discussion. First, the national drugs registry only collects data on prescribed medications and not the indication for the issued prescription. This could lead to unidentified confounding factors not adjusted for in the current analysis. An additional limitation of the study is the inability to determine whether the apparent survival benefit of betablocker treatment is explained by the preoperative administration of beta-blocker therapy or if the effect comes from continued administration of beta-blockade throughout the postoperative period. In line with standard national guidelines, all patients in Sweden are initiated on their regular drug prescriptions on admission to hospital. Therefore, an assumption of the current study is that patients continued to receive their beta-blocker throughout the majority of the duration of their hospital admission. Beta-blocker prescriptions issued following the hospital stay were also checked to ensure that beta-blocker exposed patients were continued on their preoperative beta-blocker regime following discharge. The question of hospital drug administration can, however, not be answered fully due to the retrospective nature of the study and requires an interventional design with the use of a randomised allocation procedure of the intervention studied. Although the majority of patients were prescribed metoprolol as the preferred beta-blocker, the current study does include a certain mix of beta-blocking agents. Its design also allows for a range of time intervals between drug administration and start of surgery. These are variables that would be preferable to control in order to reduce the impact of potential bias.

\section{CONCLUSION}

This large cohort study demonstrates a substantial positive effect associated with beta-blocker use on both short- and long-term mortality in patients undergoing elective colon cancer surgery. While awaiting results of future randomised trials, the current study corroborates previous findings that beta-blocker therapy is associated with a significant protective effect on overall outcome after major non-cardiac surgery.

Contributors SM, RA, PM and OL conceived and designed this study. SM, RA, PM, GS and GW acquired the data. SM, GS, RA and YC analysed the data, which was interpreted by all authors. All authors participated in drafting and critically revising the manuscript.

Funding Funding for this study was received from the Örebro University Research Committee.

Competing interests None declared.

Patient consent for publication Not required.

Ethics approval Ethical approval was obtained from the Regional Review Board, Uppsala County, Sweden (number: 2015/454 and 2015/454/1).

Provenance and peer review Not commissioned; externally peer reviewed.

Data availability statement Data are available upon reasonable request. Information in this manuscript are de-identified participant data. Data may be available on reasonable request after approval by the regional review board from the corresponding author Dr Mohseni on email mohsenishahin@yahoo.com.

Open access This is an open access article distributed in accordance with the Creative Commons Attribution Non Commercial (CC BY-NC 4.0) license, which permits others to distribute, remix, adapt, build upon this work non-commercially, and license their derivative works on different terms, provided the original work is properly cited, appropriate credit is given, any changes made indicated, and the use is non-commercial. See: http://creativecommons.org/licenses/by-nc/4.0/. 


\section{ORCID iDs}

Yang Cao http://orcid.org/0000-0002-3552-9153

Shahin Mohseni http://orcid.org/0000-0001-7097-487X

\section{REFERENCES}

1 Kwaan MR, Al-Refaie WB, Parsons HM, et al. Are right-sided colectomy outcomes different from left-sided colectomy outcomes? JAMA Surg 2013;148:504-10.

2 Morris EJA, Taylor EF, Thomas JD, et al. Thirty-day postoperative mortality after colorectal cancer surgery in England. Gut 2011;60:806-13.

3 Tiefenthal M, Asklid D, Hjern F, et al. Laparoscopic and open rightsided colonic resection in daily routine practice. A prospective multicentre study within an enhanced recovery after surgery (ERAS) protocol. Colorectal Dis 2016;18:187-94.

4 Cohen ME, Bilimoria KY, Ko CY, et al. Development of an American College of surgeons national surgery quality improvement program: morbidity and mortality risk calculator for colorectal surgery. J Am Coll Surg 2009;208:1009-16.

5 Anderson ADG, McNaught CE, MacFie J, et al. Randomized clinical trial of multimodal optimization and standard perioperative surgical care. Br J Surg 2003;90:1497-504.

6 Basse L, Thorbøl JE, Løssl K, et al. Colonic surgery with accelerated rehabilitation or conventional care. Dis Colon Rectum 2004;47:271-8.

7 Gatt M, Anderson ADG, Reddy BS, et al. Randomized clinical trial of multimodal optimization of surgical care in patients undergoing major colonic resection. Br J Surg 2005;92:1354-62.

8 Desborough JP. The stress response to trauma and surgery. $\mathrm{Br} J$ Anaesth 2000;85:109-17.

9 Lindenauer PK, Pekow P, Wang K, et al. Perioperative beta-blocker therapy and mortality after major noncardiac surgery. $N$ Engl $\mathrm{J}$ Med 2005;353:349-61.

10 Kwon S, Thompson R, Florence M, et al. $\beta$-blocker continuation after noncardiac surgery. Arch Surg 2012;147:467-73.

11 Boersma E, Kertai MD, Schouten O, et al. Perioperative cardiovascular mortality in noncardiac surgery: validation of the Lee cardiac risk index. Am J Med 2005;118:1134-41.

12 Mangano DTet al. Long-term cardiac prognosis following noncardiac surgery. JAMA 1992;268:233-9.

13 Devereaux PJ, Goldman L, Cook DJ, et al. Perioperative cardiac events in patients undergoing noncardiac surgery: a review of the magnitude of the problem, the pathophysiology of the events and methods to estimate and communicate risk. CMAJ 2005;173:627-34.

14 Dawood MM, Gutpa DK, Southern J, et al. Pathology of fatal perioperative myocardial infarction: implications regarding pathophysiology and prevention. Int J Cardiol 1996;57:37-44.

15 Rough J, Engdahl R, Opperman K, et al. Beta2 adrenoreceptor blockade attenuates the hyperinflammatory response induced by traumatic injury. Surgery 2009;145:235-42.

16 Friese RS, Barber R, McBride D, et al. Could beta blockade improve outcome after injury by modulating inflammatory profiles? J Trauma 2008;64:1061-8

17 Macchia A, Romero M, Comignani PD, et al. Previous prescription of $\beta$-blockers is associated with reduced mortality among patients hospitalized in intensive care units for sepsis. Crit Care Med 2012:40:2768-72.

18 Uchida I, Asoh T, Shirasaka C, et al. Effect of epidural analgesia on postoperative insulin resistance as evaluated by insulin clamp technique. Br J Surg 1988;75:557-62.

19 Sato H, Carvalho G, Sato T, et al. The association of preoperative glycemic control, intraoperative insulin sensitivity, and outcomes after cardiac surgery. J Clin Endocrinol Metab 2010;95:4338-44.

20 de Visser KE, Eichten A, Coussens LM. Paradoxical roles of the immune system during cancer development. Nat Rev Cancer 2006;6:24-37.

21 Ahl R, Matthiessen P, Fang X, et al. Beta-blockade in rectal cancer surgery: a simple measure of improving outcomes. Ann Surg 2018.

22 Ahl R, Matthiessen P, Fang X, et al. Effect of beta-blocker therapy on early mortality after emergency colonic cancer surgery. $\mathrm{Br} J$ Surg 2019;106:477-83.

23 SCRCR. Swedish colorectal cancer registry. Available: http:// kvalitetsregister.se/englishpages/findaregistry/registerarkivenglish/ swedishcolorectalcancerregistryscrcr.2156.htm [Accessed 24 Feb 2018].

24 Svenska Kolorektalcancerregistret (SCRCR). Nationellt kvalitetsregister för tjock- och ändtarmscancer. Available: https:// www.cancercentrum.se/samverkan/cancerdiagnoser/tjocktarmandtarm-och-anal/tjock--och-andtarm/kvalitetsregister/ [Accessed 21 Jan 2018].

25 FoU I Sverige (Researchweb). Effekt av beta-blockad på morbiditet och mortalitet vid kolorektalkirurgi för cancer. Available: https:// www.researchweb.org/is/sverige/project/228871 [Accessed 13 Sep 2018].

26 Royall RM. Model robust confidence intervals using maximum likelihood estimators. Int Stat Rev / Rev Int Stat 1986;54:221-6.

27 Johansson PI, Stensballe J, Rasmussen LS, et al. High circulating adrenaline levels at admission predict increased mortality after trauma. J Trauma Acute Care Surg 2012;72:428-36.

28 Ljungqvist $\mathrm{O}$, Scott M, Fearon KC. Enhanced recovery after surgery: a review. JAMA Surg 2017;152:292-8.

29 Halter JB, Pflug AE, Porte D. Mechanism of plasma catecholamine increases during surgical stress in man. J Clin Endocrinol Metab 1977;45:936-44.

30 Blessberger H, Kammler J, Domanovits H, et al. Perioperative betablockers for preventing surgery-related mortality and morbidity. In: Blessberger H, ed. Cochrane database Syst Rev. Chichester, UK: John Wiley \& Sons, Ltd, 2018: 104. 27-41.

31 Eagle KA, Guyton RA, Davidoff R, et al. ACC/AHA 2004 guideline update for coronary artery bypass graft surgery: summary article. $J$ Am Coll Cardiol 2004;44:1146-54.

32 Shojania KG, Duncan BW, McDonald KM, et al. Making health care safer: a critical analysis of patient safety practices. Evid Rep Technol Assess 2001;43:1-668.

33 Mangano DT, Layug EL, Wallace A, et al. Effect of atenolol on mortality and cardiovascular morbidity after noncardiac surgery. $N$ Engl J Med Overseas Ed 1996;335:1713-21.

34 , Devereaux PJ, Yang H, et al, POISE Study Group. Effects of extended-release metoprolol succinate in patients undergoing noncardiac surgery (POISE trial): a randomised controlled trial. Lancet 2008;371:1839-47

35 Bangalore S, Wetterslev J, Pranesh S, et al. Perioperative $\beta$ blockers in patients having non-cardiac surgery: a meta-analysis. The Lancet 2008;372:1962-76.

36 Juul AB, Wetterslev J, Gluud C, et al. Effect of perioperative beta blockade in patients with diabetes undergoing major non-cardiac surgery: randomised placebo controlled, blinded multicentre trial. BMJ 2006;332:1482-8.

37 Schmitz D, Wilsenack K, Lendemanns S, et al. Beta-adrenergic blockade during systemic inflammation: impact on cellular immune functions and survival in a murine model of sepsis. Resuscitation 2007;72:286-94.

38 Obeid T, Arhuidese I, Gaidry A, et al. Beta-blocker use is associated with lower stroke and death after carotid artery stenting. J Vasc Surg 2016;63:363-9.

39 Childers WK, Hollenbeak CS, Cheriyath P. $\beta$-blockers reduce breast cancer recurrence and breast cancer death: a meta-analysis. Clin Breast Cancer 2015;15:426-31.

40 Chang A, Le CP, Walker AK, et al. $\beta 2$-adrenoceptors on tumor cells play a critical role in stress-enhanced metastasis in a mouse model of breast cancer. Brain Behav Immun 2016;57:106-15.

41 Jansen L, Hoffmeister M, Arndt V, et al. Stage-specific associations between beta blocker use and prognosis after colorectal cancer. Cancer 2014;120:1178-86.

42 Tang J, Li Z, Lu L, et al. $\beta$-adrenergic system, a backstage manipulator regulating tumour progression and drug target in cancer therapy. Semin Cancer Biol 2013;23:533-42.

43 Hiller JG, Perry NJ, Poulogiannis G, et al. Perioperative events influence cancer recurrence risk after surgery. Nat Rev Clin Oncol 2018;15:205-18.

44 Hiller JG, Cole SW, Crone EM, et al. Preoperative $\beta$-blockade with propranolol reduces biomarkers of metastasis in breast cancer: a phase II randomized trial. Clin Cancer Res 2020;26:1803-11.

45 Weberpals J, Jansen L, Carr PR, et al. Beta blockers and cancer prognosis - the role of immortal time bias: a systematic review and meta-analysis. Cancer Treat Rev 2016;47:1-11.

46 Shah SM, Carey IM, Owen CG, et al. Does $\beta$-adrenoceptor blocker therapy improve cancer survival? findings from a population-based retrospective cohort study. Br J Clin Pharmacol 2011;72:157-61.

47 Jansen L, Below J, Chang-Claude J, et al. Beta blocker use and colorectal cancer risk: population-based case-control study. Cancer 2012;118:3911-9. 